\title{
Quem somos? Uma abordagem epistemológica sobre a Geometria Gráfica e suas práticas
}

\author{
Who we are? An Epistemologicall Approach to \\ Graphical Geometry and its Practices
}

\author{
Andiara Valentina de \\ Freitas e Lopes \\ Doutora em Desenvolvimento \\ Urbano \\ Docente do Departamento de \\ Expressão Gráfica; \\ Universidade Federal de \\ Pernambuco, Recife, Brasil \\ andiaralopes@yahoo.com
}

\section{Maximiliano Carneiro-da- Cunha}

Doutor em Antropologia Docente da Universidade Federal Rural de Pernambuco UFRPE/UAST, Serra Talhada, Brasil

maxcarneiro6@gmail.com

\section{Mariana Buarque Ribeiro de Gusmão}

Doutora em Engenharia Civil Docente do Departamento de Expressão Gráfica; Universidade Federal de Pernambuco, Recife, Brasil marianagusmao@gmail.com

\section{RESUMO}

Esse trabalho tem como objetivo fazer uma reflexão epistemológica a respeito da Geometria Gráfica, de suas representações e do estudo da Forma como objeto de estudo. A ideia central partiu de questionamentos sobre os motivos que levaram a Geometria Gráfica a se encontrar na posição atual de desvalorização acadêmica. Isto inclui a retirada da disciplina do currículo escolar brasileiro, a falta de consenso com relação à identidade dos profissionais, bem como às mudanças de paradigma trazidas pelas novas tecnologias. Nesse sentido, procurou-se discutir: 1) a origem e desenvolvimento da disciplina no Brasil; 2) a identidade da Geometria Gráfica como ciência, cujo resultado final está vinculado ao estudo e a representação gráfica da Forma; 3) suas práticas, que durante muito tempo foramse fragmentando devido ao uso de diferentes nomenclaturas, tais como "desenho", "desenho técnico", "desenho geométrico", "expressão gráfica", entre outras; e 4) seu futuro como área do conhecimento, diante das diferentes perspectivas de atuação com as novas tecnologias digitais. Ao final, pudemos compreender que o termo Geometria Gráfica define melhor e de maneira mais eficaz esta área de estudo estabelecendo, de uma maneira objetiva, que o nosso objeto de estudo é a Forma em suas diferentes representações.

Palavras-chave: geometria gráfica; representação gráfica; desenho; representação

\section{ABSTRACT}

This work aims to make an epistemological reflection about Graphic Geometry, its representations and the study of the Form as a study object. The central idea has arisen from the reasons that led Graphic Geometry to a position of academic devaluation. This includes the withdrawal of the discipline from the Brazilian school curriculum, the lack of consensus regarding the identity of its professionals, as well as the paradigm changes brought about by the new technologies. In this sense, we tried to discuss: 1) the origin and development of this discipline in Brazil; 2) the identity of Graphic Geometry as a science, which is linked to both the study and the graphic representation of the Form; 3) its practices, which has been fragmented due to the use of different nomenclatures such as "drawing", "technical drawing", "geometric drawing", "graphic expression", among others; 4) its future as an area of knowledge facing different prospects of action with the new digital technologies. At the end, we were able to understand that the term Graphic Geometry defines this area of study in a better and more effective way, since it establishes that our object of study is the Form in its different representations.

Keywords: graphical geometry; graphic representation; drawing; representation 


\section{INTRODUÇÃO}

A Geometria tem origem há milhares de anos e sempre se preocupou com o estudo da Forma, mesmo que do ponto de vista algébrico e analítico próprios da Matemática. Dessa maneira, a Geometria e a Matemática sempre foram vistas como ciências gêmeas e inseparáveis. No entanto, no mundo ocidental a história mais recente nos mostra como a Matemática se separa da Geometria sob vários aspectos, especialmente político-didático, chegando ao ponto de hoje em dia o pouco conteúdo de Geometria presente nos currículos escolares brasileiros serem abordados sob a ótica exclusiva da Matemática, com a Álgebra no Ensino Básico e a Analítica no Ensino Superior. Não obstante, a importância da Geometria é reconhecida desde o início da civilização humana, quando foi criada com o intuito de conhecer e entender os conceitos matemáticos de multiplicidade e espaço, envolvendo o estudo de áreas e volumes (terra, água, etc.).

Este artigo parte de uma inquietação epistemológica acerca da Geometria, mais especificamente da Geometria Gráfica como área de estudo e pesquisa. Tomamos como base a experiência docente de ensino dentro do Departamento de Expressão Gráfica (DEG) da UFPE, da elaboração do projeto de pós-graduação e do Projeto Pedagógico de Curso (PPC) do curso de Licenciatura em Expressão Gráfica (LEG), ambos para o mesmo departamento, para construção de uma reflexão mais densa a respeito do próprio entendimento da Geometria Gráfica como ciência e área de ensino.

A partir da experiência com ensino e pesquisa no DEG, detectamos uma dificuldade antiga em definir a identidade da Geometria Gráfica de forma consensual. Essa dificuldade pode ser identificada na própria definição do nome do nosso departamento, Expressão Gráfica, nome que acreditamos não ser o mais apropriado, uma vez que "expressão" se refere apenas a uma das vias da síntese gráfica, quando a outra seria a "interpretação" gráfica. Se fossemos seguir essa lógica o nome mais apropriado para o departamento seria "Síntese Gráfica". Nesse ponto alguém poderia nos perguntar: qual seria então o nome mais apropriado? Em princípio acreditamos que um nome adequado seria "Comunicação Gráfica", que se relaciona aos usos feitos da Geometria. Mas, ainda assim seria limitado, pois entendemos que a Geometria Gráfica não se limita a ser apenas uma linguagem. Dessa maneira, deveríamos procurar um nome abrangente, tanto nas práticas empíricas como na teoria. Assim sendo, o nome mais acertado seria "Geometria", mais especificamente "Geometria Gráfica". No entanto, entendemos que o nome "Expressão Gráfica" é, nesse momento, estrategicamente mais apropriado, uma vez que relaciona nosso departamento (DEG) e nosso curso (LEG) com outros semelhantes no Brasil. Enfim, o fato é que a própria dificuldade em definir um nome próprio da área já demonstra o tamanho da crise de identidade que nós, profissionais desse campo de conhecimento enfrentamos ao longo do tempo. 
Entretanto, a nossa identidade, e por consequência o nosso nome, estão ligados fundamentalmente às nossas práticas de ensino e pesquisa. Acreditamos que ao definir que práticas são estas, poderemos entender melhor nossa identidade. Em outras palavras, acreditamos que a Geometria Gráfica está hoje fragmentada na sua própria concepção e, portanto, enfraquecida como área do conhecimento. Entender por que a Geometria Gráfica se encontra tão desvalorizada e não reconhecida é importante para construirmos uma identidade consensual, forte e direcionada, proporcionando estudos e práticas de ensino mais reflexivas e atualizadas.

Esse trabalho tem como objetivo fazer uma reflexão epistemológica a respeito da Geometria, da representação gráfica e do desenho na área da Geometria Gráfica. 0 escopo central desse artigo é entender a dificuldade em estabelecer a Geometria Gráfica como área de estudo imprescindível na formação de profissionais que trabalham com a Forma e o porquê da sua desvalorização generalizada nas instituições de ensino no Brasil. Nesse sentido, a pergunta que se apresenta nesse trabalho é: até que ponto a utilização dos termos "desenho" e "expressão" limitam o entendimento de Geometria Gráfica em toda sua dimensão e especificidade? Até que ponto uma definição equivocada e limitante de quem somos e quais são nossas práticas impedem o nosso desenvolvimento e nosso reconhecimento como área do saber científico, imprescindível para se trabalhar a Forma? Diante disso, esse artigo foi estruturado em função de quatro perguntas: de onde viemos? Quem somos? O que fazemos? E para onde vamos?

Para fundamentar esse questionamento, tomaremos como ponto de partida os conceitos teóricos e práticos fundamentais da disciplina, passando pelo desenvolvimento e pelos problemas de valorização dela no Brasil, definindo quem somos e as nossas práticas e finalizando com uma reflexão sobre que caminhos teremos no futuro. No entanto, é necessário se fazer uma ressalva. Tomando como ponto de partida o cenário geral da Geometria Gráfica é possível afirmar que ela, como ciência, ao longo de sua história, chegou a um estado de adormecimento. Há muitos anos não se formulam novas teorias, postulados, axiomas e teoremas, ficando difícil, portanto, traçar sua história sem remontar a um passado muito distante e já bastante explorado pela literatura. 0 seu desenvolvimento mais moderno se limitou às práticas ligadas ao seu Ensino.

Por todas essas razões, esse trabalho se justifica pela importância do entendimento da Geometria Gráfica como ciência e, consequentemente, como disciplina fundamental para áreas do conhecimento que trabalham com a Forma como objeto, a exemplo da Arquitetura, Engenharias, Design, entre outras. Assim sendo, esse artigo visa contribuir para uma análise epistemológica da Geometria Gráfica como ciência, repensando-a como meio para representar a Forma nas suas mais diversas funções. 


\section{GEOMETRIA GRÁFICA}

Tomando como base a pergunta norteadora desse trabalho, a qual questiona a base identitária da Geometria Gráfica, assim como o entendimento do nosso objetivo último - que é o estudo da Forma - faremos um apanhado dos principais conceitos que fundamentam esta área, para então discorrer sobre os atuais problemas em que se encontra a prática da Geometria Gráfica. A ideia é tentar responder às quatro perguntas subjacentes ao questionamento central, ou seja, de onde viemos, quem somos, o que fazemos e para onde vamos? Acreditamos que as respostas a estas questões podem fornecer uma compreensão do porquê de a Geometria Gráfica não ter a devida valorização no cenário educacional brasileiro.

\subsection{De onde viemos? Uma breve história da Geometria Gráfica no Brasil}

Um histórico da evolução, pesquisa e ensino do desenho técnico é traçado por Ulbricht (1998). Seu estudo mostra enfoques desde de a idade média e se estende até os dias atuais, como advento da era da informática e do universo virtual. $\mathrm{O}$ autor mostra que na França o aprendizado do desenho e da Geometria era um ofício estudado na prática de uma profissão e, como aos poucos, foi se profissionalizando até se conformar em uma disciplina nas academias no século XVII, culminando com a fundação da Academia Real de Arquitetura em 1671. No que diz respeito aos conceitos de desenho, Bueno (2011) apresenta uma revisão desse tema em Portugal entre os séculos XVI e XVIII, com o objetivo de demonstrar a seriedade e relevância desse campo do conhecimento para a Coroa Portuguesa. Seu trabalho mostra como Portugal investiu na formação de um quadro de profissionais habilitados nessa área e de como isso foi utilizado na sua política expansionista no século XVI.

Segundo Ulbricht (1998), o grande impulso dado ao ensino do desenho no Brasil acontece depois da chegada de D. João VI ao país, na missão artística de 1816 que, além de artistas, trouxe também um arquiteto, um engenheiro mecânico e alguns mestres de ofícios nesta especialidade. No Brasil, o ensino da Geometria possui uma história particular, marcada por acontecimentos políticos, sociais e econômicos, que infelizmente culminou com o quase abandono do seu ensino básico nas escolas brasileiras. Pavanello (1989; 1993) se refere ao "desaparecimento" da Geometria dos currículos escolares, questionando o porquê de a Geometria ter perdido sua importância e o seu valor. Conforme a autora, as explicações para esse fato são advindas de diversos fatores sociais, políticos e econômicos. Pavanello (ibid.) defende ainda a tese de que o ensino da Geometria no Brasil passou, e passa, por um gradual desaparecimento do currículo escolar nas últimas décadas, fato que preocupa bastante alguns educadores. A principal causa para esse fato, segundo ela, seria a promulgação da Lei 5692/71 (BRASIL, 1971). 
No início do século XX, por ser o Brasil majoritariamente agrícola, a maioria da população era analfabeta devido ao escasso acesso à Educação, mesmo a Básica, quando o ensino da Matemática e da Geometria era puramente utilitário. Para as poucas pessoas que tinham acesso à Educação Secundária, com acesso particular, o ensino da Matemática era abstrato e não refletia preocupações com as questões práticas. A Matemática era dividida em Aritmética, Álgebra e Geometria, ensinadas como disciplinas separadas e por diferentes professores (PAVANELLO, 1993).

Após a primeira guerra mundial, no entanto, o Brasil passa por modificações políticas, sociais e econômicas que afetam a Educação, especialmente na reivindicação ao combate do analfabetismo. Nessa época os analfabetos não tinham direito ao voto e o interesse era reverter esse quadro. Após a crise de 1929, o Brasil passa por um processo de crescimento da indústria, no qual o ensino da Matemática e da Geometria tornou-se necessário (PAVANELLO, 1993).

Na década de 1930 ocorreram muitas mudanças no Brasil que afetaram diretamente a Educação, como a criação do Ministério da Educação e Saúde; a criação das Universidades em São Paulo e Rio de Janeiro, com cursos específicos para formação de professores; e a Constituição de 1934, que estabelece a responsabilidade do Estado com relação à Educação no Brasil. Com relação ao ensino da Matemática e suas divisões, a Reforma Francisco Campos orientava que o ensino das disciplinas de Álgebra, Aritmética e Geometria fosse unificado em apenas uma matéria, ou seja, a Matemática. Essas mudanças foram impostas a nível nacional. No entanto, Pavanello afirma que, "o exame dos livros didáticos da época mostra que os temas (Aritmética, Álgebra e Geometria) são programados em cada série, sem que exista a preocupação em trabalhá-los integralmente" (PAVANELLO, 1993, p. 5), fato que mostra uma discrepância com relação a orientação feita pela Reforma.

Na década de 1940, o Brasil passa por novos processos de transformação social, política e econômica, devido aos processos de desenvolvimento de urbanização e industrialização. 0 Governo investe na Educação Profissional para qualificar trabalhadores ao mesmo tempo que tenta conter as agitações sociais (Reforma Gustavo Capanema de 1942). Quanto ao ensino da Geometria, a orientação ocorria a partir de explorações intuitivas, para só então se chegar à exposição formal, ou seja:

Os programas de matemática de 1942 apresentam algumas diferenças em relação aos de 1931. Não mais se insiste em que os três assuntos (aritmética, álgebra e geometria) sejam abordados em cada uma das séries do curso ginasial. A geometria, no entanto, é abordada nas quatro séries, intuitivamente nas duas séries iniciais e dedutivamente nas últimas. Ela é também bastante priorizada no segundo ciclo, constando da programação de todas as séries. Inclui-se ainda trigonometria no $2^{\circ}$ ano e geometria analítica no $3^{\circ}$ ano. (PAVANELLO, 1993, p. 5). 
Os programas propostos pela Reforma Capanema são recebidos com muitas críticas no geral e em especial o de Matemática. As críticas eram em relação ao fato de os programas serem muito longos, o que tornaria o ensino nas escolas meramente conteudista. Sendo assim, em 1951, o Ministro da Educação Simões Filho, propõe uma nova reforma, na qual os programas deveriam se adaptar ao tempo e permitir ajustes às diferenças regionais do país. A Geometria deixa de constar na segunda série ginasial e concentra-se no primeiro ano do segundo ciclo, ao passo que a Geometria Analítica é ensinada no terceiro ano (PAVANELLO, 1993).

Nas décadas de 1950 e 1960 o Brasil continua passando pelo processo de urbanização e industrialização, agora de forma mais acelerada, tendo como consequência a expansão da rede escolar. A Lei 4024/61(BRASIL, 1961) das Diretrizes e Bases da Educação Nacional (que no futuro seria revogada pela Lei no 9.394/96) (BRASIL, 1996), considera que nas três primeiras séries devem ser ensinados conteúdos mais utilitários e nas séries finais os conteúdos podem ressaltar suas relações com as demais disciplinas da formação geral. Assim, o ensino da Geometria, mais especificamente, o desenho geométrico, tornou-se uma disciplina complementar obrigatória, podendo ser escolhida dentre outras disciplinas para agregar o currículo escolar.

No início da década de 1960, o Brasil passa a ter influência do Movimento da Matemática Moderna (MMM), cuja ideia é melhorar o ensino da Matemática - que têm muitos problemas no mundo todo - através da adaptação desta às novas concepções surgidas ao longo dos anos, tanto no campo da Matemática propriamente dita, como no campo da Didática. Com isso, a Álgebra e a Analítica passam a ser hegemônicas nessa nova estrutura. É nessa linha de pensamento que é implementada a Lei 5692/71, Lei de Diretrizes e Bases do Ensino de $1^{\circ}$ e $2^{\circ}$ graus (BRASIL, 1971), com o objetivo profissionalizar o Ensino Médio e conceder a liberdade para as instituições de ensino para montarem seus próprios currículos para as disciplinas. Dessa maneira, o ensino da Matemática se foca na aritmética e nas noções de conjunto.

Com relação à Geometria, a orientação é que os livros acentuem as noções de figura geométrica e interseção de figuras, mas para adaptar-se ao paradigma vigente (MMM) as representações geométricas adotam a linguagem da teoria dos conjuntos. A Geometria é trabalhada de forma intuitiva, utilizando teoremas como postulados para resolver problemas e "não existe qualquer preocupação com a construção de uma sistematização a partir de noções primitivas e empiricamente elaboradas" (PAVANELLO, 1993, p.7). Outro ponto relevante é a exigência em se trabalhar a Geometria sob o enfoque das transformações. Porém, a maioria dos professores de matemática não domina esse conteúdo e, deste modo, muitos deixam de ensinar a Geometria, sob qualquer aspecto. É assim que a Geometria vai deixando gradativamente de ser ensinada nas escolas públicas brasileiras, apesar de continuar a ser ensinada nas escolas particulares e militares. 
Um dos desdobramentos da Lei 5.692/71 (BRASIL, 1971) foi a inteira exclusão da Geometria das provas dos vestibulares de acesso ao Ensino Superior na década de 70. Para Barros e Bellemain (2013) esse foi o maior golpe no ensino da Geometria - sendo tratada pelos autores como Desenho pois as escolas deixaram de incluir essa disciplina em seu currículo, como lhes faculta a lei, e que agora passa a ser uma disciplina que trabalha um conteúdo que não é mais exigido nos concursos vestibulares.

Um outro fator importante para o entendimento do processo de desvalorização do ensino da Geometria nas escolas públicas brasileiras é o fato de que no Brasil a Geometria Gráfica foi aliada às artes, especialmente no Ensino Superior. Ana Mae Barbosa (2015) faz uma análise do desenvolvimento da Geometria no Brasil entre os séculos XIX e XX e mostra como a história do ensino da Geometria e do desenho estão ligados ao ensino das artes, inclusive apontando o entendimento na época de que esses conhecimentos fossem ensinados a todas as pessoas. Infelizmente, o ensino das artes, incluindo-se Expressão Artística, Artes Plásticas, Música e Teatro possuem uma história de pouca valorização no Brasil, especialmente no tocante à Educação. 0 currículo da Educação Básica brasileira para o ensino das artes é, em geral, desvalorizado. Uma vez que o ensino da Geometria se associa ao das artes, ele alcança o mesmo nível de desvalorização dado a este.

No Ensino Superior, concomitantemente à Lei 5.692 (BRASIL, 1971), o Ministério da Educação promoveu a unificação de alguns dos cursos de licenciatura. No tocante à Geometria (tratada como "desenho") houve a criação da Licenciatura em Educação Artística, que contava com uma formação polivalente e geral nos primeiros dois anos e uma formação específica nos dois últimos anos. Dessa forma, os conteúdos das diversas áreas das artes, como Música, Teatro, Artes Plásticas e Desenho (Geometria) estavam unificados em um único curso chamado Licenciatura em Educação Artística. Essa história é muito perceptível quando falamos do histórico do curso de Professorado em Desenho que funcionou até esta época na Escola de Belas Artes no Recife, contemplando os conteúdos de Geometria, mas que após essa reforma foi extinto (BARROS e BELLEMAIN, 2013).

Com relação ao curso de Licenciatura em Expressão Gráfica, sua história remonta ao curso de Licenciatura em Desenho e Plástica (LDP) de 1961. Este último originou-se do curso de Professorado em Desenho da Universidade do Recife, o qual foi criado em 1951. Segundo registros, a criação do curso de Professorado em Desenho se deu em função da deficiência didática de engenheiros e arquitetos, que tradicionalmente lecionavam "Desenho". Como mencionamos acima, na década de 40 , todas as disciplinas de Matemática foram unificadas e a Geometria sofreu as consequências dessa modificação ficando relegada aos últimos anos. A Geometria (Desenho ou ainda Desenho Geométrico), ainda persistiu como disciplina obrigatória dos cursos de nível Fundamental II e Médio (antigo "ginasial" e "científico") nas décadas de 1950 e 1960, mas foi, cada vez mais, reduzida à simples memorização de receitas de traçado. 
Diante dessa realidade, os cursos superiores remediavam a situação do acúmulo dessa deficiência em seu suporte teórico. Na década de 1960, por exemplo, os cursos de Engenharia, incluíam em seu currículo mais de 500 horas de disciplinas específicas de Desenho (atualmente, esse número foi reduzido à menos da metade). No final dessa década, a demanda pelo curso de Professorado em Desenho era bastante reduzida. Numa tentativa de conquistar um mercado de trabalho mais amplo, que atraísse melhores candidatos ao vestibular, tal curso foi transformado no Curso de Licenciatura em Desenho e Plástica, absorvendo assim o curso superior de Pintura e Escultura, que estava funcionando sem o reconhecimento do Ministério da Educação e Cultura (MEC), durante muitos anos, na Escola de Belas Artes (BARROS E BELLEMAIN, 2013).

Muito tempo depois, em 1993, o curso de Licenciatura em Desenho e Plástica passou por uma profunda mudança no seu perfil com o objetivo de adequar-se às necessidades do então mercado globalizado, aproximando os egressos das então denominadas "novas tecnologias", vinculadas aos diferentes instrumentos computacionais. As mudanças realizadas também se refletiram positivamente nas discussões levadas a efeito nos congressos promovidos pela ABPGDDT (Associação Brasileira de Professores de Geometria Descritiva e Desenho Técnico), atualmente ABEG (Associação Brasileira de Expressão Gráfica).

Em 2006, o MEC implantou novas exigências para os cursos nacionais de formação de professores. 0 Colegiado do Curso de Licenciatura em Desenho e Plástica entendeu que ao adaptar a estrutura curricular do curso às exigências do MEC, havia a necessidade de se levar em consideração a influência das novas tecnologias computacionais, as mudanças de mercado, as constantes transformações sociais e a reflexão sobre a formação do egresso do curso. Assim, em 2010, foi implantado o curso de Licenciatura em Expressão Gráfica, cujo perfil do profissional licenciado é mais voltado para a Geometria Gráfica e suas aplicações e, portanto, mais adaptado à realidade e demandas vigentes. Acreditamos, que a exemplo desse curso, que fez uma opção em se desassociar das artes e se associar às tecnologias computacionais, a Geometria Gráfica tem a possibilidade de avançar e se desenvolver mais plenamente ao criar mais possibilidades de discussão do seu papel na produção de conhecimento e na sua própria construção como Ciência da Forma.

Consideramos, até agora, os motivos históricos (políticos, sociais e econômicos) que contribuíram para o "desaparecimento" dos conteúdos de Geometria dos currículos nacionais de Educação Básica. Entretanto, a análise somente desse aspecto mostra apenas um dos lados na busca pelas causas da desvalorização da Geometria no Brasil e por esse motivo precisamos continuar essa reflexão, nos aprofundando um pouco mais na discussão sobre quem somos e sobre a necessidade clara do entendimento da Geometria Gráfica como uma Ciência. 


\title{
2.2 Quem somos? A Geometria Gráfica como ciência
}

A literatura mundial salienta a importância do aprendizado dos conteúdos da Geometria Gráfica para o pleno desenvolvimento cognitivo de crianças e jovens. Nesse sentido, inúmeros trabalhos e pesquisas nos mostram a grande perda cognitiva em crianças e jovens quando estes não têm contato com essa área de conhecimento específico (PIAGET, J.; INHELDER, 1993; LORENZATO, 1995; NASSER, 2000; FÜRKOTTER, M.; MORELATTI, 2009). Estudar Geometria Gráfica ajuda a desenvolver habilidades cognitivas, que não são usualmente desenvolvidas através do estudo de outras matérias. Dentre essas habilidades estão o raciocínio abstrato e espacial, a coordenação motora, a síntese gráfica, o senso de proporção e escala, a memória visual, a visomotricidade e a criatividade (GARDNER, 1994).

Vivemos em um mundo tridimensional, tudo, absolutamente tudo, a nossa volta possui três dimensões. Nosso corpo, nossas experiências sensoriais são tridimensionais e, consequentemente, a relação que temos com o mundo é espacializada. A Geometria Gráfica, por estudar a Forma, o espaço e a relação das formas no espaço pode contribuir sobremaneira para a compreensão e formalização dessa série de conhecimentos que para todos nós é natural e intuitiva. Lorenzato (2006) enfatiza que a criança realiza suas primeiras experiências de vida utilizando os cinco sentidos, mas especialmente a visão, utilizando a percepção espacial para fazer descobertas. Por isso é fundamental estimular a criança a explorar o espaço a sua volta, uma vez que o processo de aprendizagem ocorre através das ações mentais de distinção, comparação, separação e montagem.

\begin{abstract}
Sem estudar Geometria as pessoas não desenvolvem o pensar geométrico ou o raciocínio visual e, sem essa habilidade, elas dificilmente conseguirão resolver as situações de vida que forem geometrizadas; também não poderão se utilizar da Geometria como fator altamente facilitador para a compreensão e resolução de questões de outras áreas de conhecimento humano. Sem conhecer Geometria a leitura interpretativa do mundo torna-se incompleta, a comunicação das ideias fica reduzida e a visão da Matemática torna-se distorcida (LORENZATO, 1995, p. 5).
\end{abstract}

Búrigo (2005) destaca quatro conjuntos de justificativas para se ensinar e aprender Geometria. 0 primeiro conjunto consiste no desenvolvimento da percepção e da representação do espaço físico, tanto do vivenciado como do imaginado e das relações entre os objetos desse espaço. Inclusive facilitando a comunicação com outras áreas do conhecimento, como a Física e a Geografia. 0 segundo conjunto envolve o desenvolvimento da capacidade de classificar, comparar e operar com figuras e sólidos. Já o terceiro conjunto de justificativas abrange a representação geométrica de conceitos ou fatos aritméticos ou algébricos, através do estudo das grandezas e da proporção. Finalmente, o quarto conjunto compreende o desenvolvimento do pensamento dedutivo relacionado aos fatos geométricos a partir da experimentação dos mesmos. 
Apesar da sua notável importância, a Geometria Gráfica não existe como área de conhecimento específica para os órgãos de fomento à pesquisa, como por exemplo o Conselho Nacional de Desenvolvimento Científico e Tecnológico (CNPq) e a Coordenação de Aperfeiçoamento de Pessoal de Nível Superior (CAPES). Tal fato demonstra que não sabemos quem somos. Melhor dizendo, tal fato demonstra que apesar da inegável importância que aprendizado desses conhecimentos pode ter na vida das pessoas, não somos reconhecidos como ciência. No entanto, nós, profissionais dessa área, tentamos nos definir. Porém, a busca por essa definição é fragmentada e geralmente mistura a definição de quem somos com as nossas práticas. Além disso, no intuito de definir quem somos, em alguns casos, nos apropriamos da identidade de outras áreas, a quem servimos como meio. Para agravar ainda mais, muitas vezes, tentamos explicar quem somos através das ferramentas que usamos, como por exemplo, a representação gráfica ou o desenho. Acreditamos que esse dissenso se deve ao fato da falta de entendimento de que a Geometria Gráfica se constitui em uma ciência e uma linguagem.

A palavra "desenho" não explica nem define nossa área de trabalho e estudo. A própria tarefa de tentar definir o termo é extremamente difícil. 0 significado do termo nos dicionários é bastante abrangente e vago. Os dicionários Houaiss (2010) e Michaelis (2018) trazem as seguintes definições para a palavra desenho:

s.m. 1 representação gráfica de objetos e ideias feita sobre uma superfície 2 representação por linhas da forma de um objeto; contorno, traçado (HOUAISS, 2010, p. 242).

s.m. 1 Representação gráfica, por meio de linhas, cores e sombras, de objetos, seres, ideias, sensações etc. 2 Arte e técnica de representar visualmente a forma desses elementos, servindo-se de linhas ou traços, assim como de efeitos de luz, cores e sombras. 3 Conjunto de procedimentos relativos a essa arte e a essa técnica. 4 Configuração do contorno de uma figura, objeto etc.; contorno, delineamento, recorte. 5 Delineamento ou traçado geral de um quadro ou de qualquer obra de arte executado por meios gráficos. 6 FIG Representação ou criação, por meios não gráficos (som, palavras, símbolos, ideias etc.), de uma forma imaginária; configuração, construção, descrição, figuração. 7 Forma ou feitio de um objeto, especialmente o contorno, considerada pelas suas qualidades plásticas; design. 8 Figura de ornatos (para tecidos, vasos, decoração em geral etc.). 9 Plano ou projeto de objetos com finalidade técnica, industrial, científica, ornamental, arquitetônica etc.; esboço, planta, risco, traçado.10 P US Idealização de um propósito ou objetivo qualquer; desígnio, intenção, plano (MICHAELIS, 2018).

Wucius Wong (1998), por sua vez, tenta definir o termo da seguinte forma, sem aprofundar o conceito. Ele afirma:

Muitas pessoas considerariam desenho como algum tipo de esforço para embelezar a aparência externa das coisas. Certamente, o mero embelezamento constitui um aspecto do desenho, porém o desenho é muito mais do que isso. (...) 0 desenho é um processo de criação visual que tem propósito. Diversamente da pintura e da escultura, que constitui a realização das visões e sonhos pessoais 
dos artistas, o desenho preenche necessidades praticas. Um trabalho de desenho gráfico deve ser colocado diante do olhar do público e transmitir uma mensagem predeterminada. Um produto industrial tem de atender as exigências dos consumidores. Um bom desenho, em resumo, constitui a melhor expressão visual possível da essência de 'algo', seja uma mensagem, seja um produto. Para executar essa tarefa de forma acurada e efetiva, o desenhista deve procurar a melhor maneira possível em que este 'algo' possa ser definido, feito, distribuído, utilizado e relacionado com o ambiente. Sua criação deve ser não somente estética, mas também funcional, ao mesmo tempo que reflete ou orienta o gosto de seu tempo (WONG, 1998, p. 41).

Recentemente, Marques et al (2017) conseguem ir mais além nas definições do termo desenho, mais especificamente o desenho técnico:

A comunicação gráfica envolve o uso de materiais e dispositivos para relacionar e transmitir ideias. (...) esboços, desenhos, imagens, diapositivos, bem como a impressão 3D, são diferentes meios que permitem a comunicação gráfica. De facto, qualquer recurso ou meio que use representações gráficas para ajudar a transmitir uma mensagem ou instrução faz parte da comunicação gráfica. Uma das formas mais comuns de comunicação gráfica é o desenho. No caso mais geral, um desenho pode ser entendido como uma representação gráfica de ideias, conceitos e entidades reais ou imaginárias. O desenho é, na verdade, uma das formas de comunicação mais antigas, que surgiu antes da comunicação verbal. De seguida são apresentadas as formas de representação gráfica mais frequentemente utilizadas nas diversas áreas, dandose particular enfoque aos diferentes tipos de desenhos. De um modo simples e abrangente, pode dizer-se que os principais tipos de desenhos usados nas representações gráficas são o desenho artístico e o desenho técnico. Este último pode ser projetivo ou não-projetivo. As representações ortográficas e perspéticas [sic] são exemplos de desenhos técnicos projetivos. Por seu lado, esboços e diagramas concretizam desenhos técnicos nãoprojetivos. (MARQUES, FLORES e SOUTO, 2017).

É um equívoco reduzir a definição da Geometria Gráfica ao termo "desenho", mesmo quando associado a adjetivos que pouco explicam, tais como "desenho geométrico" ou "desenho técnico". 0 desenho é apenas um dos meios pelos quais nos expressamos. A utilização do termo "desenho" para determinar quem somos, na verdade, nos presta um desserviço, porque nos enfraquece e nos limita como profissionais, transformando nossa identidade em algo extremamente simplista. Em última instância, a utilização do termo "desenho" para nos identificar contribui fortemente para o processo de desvalorização pelo qual passamos.

Tendo em vista toda essa reflexão, somaremos aqui as definições de Geometria dadas por Chaput (1954) e Costa (1996). O primeiro afirma que, "A Geometria é a ciência da extensão. 0 espaço é extenso sem interrupção e sem limite" (Chaput, 1954, p. 3). Já Costa nos diz que "Um objeto possui FORMA, 
FUNÇÃO e CONSTITUIÇÃO MATERIAL. A GEOMETRIA estuda apenas a FORMA do objeto, desvinculada dos outros dois fatores" (COSTA, 1996, p.14). Caminhamos para o entendimento de que a Geometria Gráfica é uma ciência, uma "ciência da extensão" como diz Chaput, o que nos leva a compreensão da abrangência da Geometria para o estudo das formas tanto bidimensionais como tridimensionais. Por conseguinte, a pessoa que trabalha com a Geometria Gráfica do ponto de vista científico é o geômetra.

A figura 1, nos mostra um quadro síntese da definição de quem somos e da relação da Geometria Gráfica com as outras áreas do conhecimento que trabalham com a Forma. Sendo uma ciência, a Geometria tem como seu objeto de estudo a Forma, desprovida de função e constituição material (COSTA, 1996). Essas formas são compostas por entes geométricos, a saber: ponto, linha e superfície. Dessa maneira, o geômetra estuda a Forma analisando os elementos que a compõe, assim como a interrelação entre esses elementos.

Figura 1: quadro síntese da definição de quem somos.

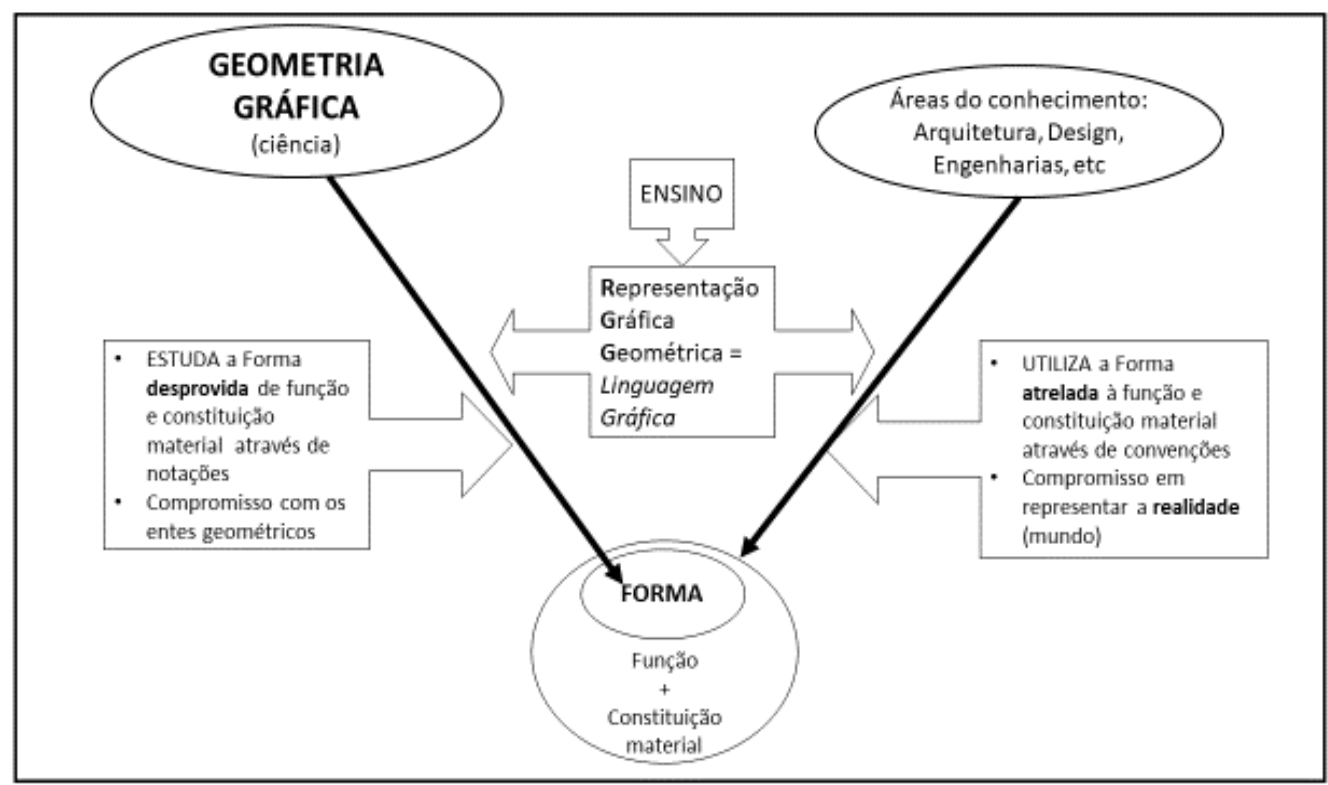

Fonte: Autores (2018)

Para estudar a Forma o geômetra necessita de um suporte gráfico (seja o desenho ou o meio digital) para representá-la. Utilizando esse suporte gráfico as formas e suas propriedades são então representadas. Tal representação chama-se Representação Gráfica Geométrica, que se constitui em uma linguagem gráfica, uma vez que serve como meio de comunicação para veicular as ideias a respeito da forma.

Atualmente, no entanto, a Geometria Gráfica como ciência se encontra em um hiato. Acreditamos que isso ocorra porque tudo que foi formulado até hoje (postulados, teoremas, etc.) ainda são suficientes para explicar e compreender a realidade vigente. Nesse ponto, o trabalho da Geometria Gráfica se limita ao ensino da linguagem gráfica para outras áreas do conhecimento que, por sua vez, precisam dela para representar e projetar as formas que utilizam. Em outas palavras, existem áreas do conhecimento, como 
a Arquitetura, o Design e as Engenharias de modo geral, que utilizam representações gráficas geométricas como produto de suas criações. Portanto, essas áreas necessitam da Geometria para se expressar graficamente através das representações gráficas, ou seja, da linguagem gráfica desenvolvidas pela Geometria Gráfica.

Em resumo, a Geometria Gráfica como ciência tem como objeto de estudo a Forma per se. No entanto, as outras áreas (Arquitetura, Design e Engenharia) utilizam a Forma como produto, resultado de um processo criativo. Gostaríamos de enfatizar que há aqui uma clara distinção entre o tratamento que cada uma dessas áreas dá à Forma. A Geometria Gráfica, como foi dito, estuda a Forma a partir dos elementos que a constituem com foco na sua conceituação, definição, caracterização e no entendimento das relações existentes entre esses elementos, como das relações e entre esses elementos e o espaço. Que requer uma série de notações específica que são necessária para a criação de teorias sobre a forma. Já a Arquitetura, o Design, as Engenharias, entres outras áreas, utilizam a Forma necessariamente atrelada a uma função e, consequentemente, a uma constituição material no intuito de representar, criar ou projetar a Forma em seus projetos. Além disso, a Forma para essas áreas está intrinsecamente compromissada com suas respectivas realidades, ou seja, as Formas são a representação de algo que já existe ou irá existir no mundo real. Para que isso ocorra, a representação gráfica deve obedecer a uma séria de convenções, propriedades, medidas, regras e padrões, fundamentados em sistemas de representação pré-estabelecidos pela Geometria Gráfica e que são comprometidos em representar a realidade. Cabe aqui, entretanto, fazer uma ressalva com relação à área do conhecimento das Artes, que também pode ser enquadrada como uma das áreas do conhecimento que utilizam e representam Formas. Porém, diferentemente das outras áreas já citadas, seu compromisso é com uma realidade subjetiva que depende inteiramente do artista.

Um desdobramento importante do entendimento do estado atual da Geometria Gráfica ocorre quando entendemos que estamos em parte adormecidos. Melhor dizendo, enquanto ciência, a Geometria Gráfica não tem avançado nas últimas décadas. Por outro lado, enquanto Representação, a Geometria Gráfica tem evoluído através do ensino, tanto da linguagem gráfica, quanto das propriedades da Forma, de modo aplicado para outras áreas, sobretudo com a presença das tecnologias digitais, nos reduzindo, portanto, a apenas uma parte do que somos. Desse modo, fica mais fácil compreender o porquê dessa enorme dificuldade em definir nossa identidade, já que muitas vezes confundimos o que somos com o que fazemos. Em outras palavras, não raro, nos definimos apenas como uma linguagem ou, pior ainda, nos definimos apenas como um dos possíveis tipos de suporte gráfico, que é o desenho. Podemos assim perceber o quão limitante é hoje o nosso entendimento sobre nós mesmos. 


\subsection{O que fazemos? A Geometria Gráfica e o estudo da Forma}

Ao longo da história, a humanidade desenvolveu diferentes formas de comunicação através de linguagens verbais e não verbais, sendo bastante difícil aprender todas as formas de linguagem para se comunicar. No entanto, as pessoas podem se comunicar eficazmente pela linguagem verbal do mesmo modo que pela não-verbal. Há pouco consenso sobre uma definição exata do que seria o termo linguagem, mas certamente a maioria dos estudos convergem no sentido de que a linguagem é um sistema baseado em regras de sinais.

Neste sentido, o termo linguagem é um sistema organizado por conteúdo (semântica), estrutura (sintaxe) e uso (pragmática), objetivando a transmissão e, consequente, o entendimento de algum tipo de conhecimento.

\footnotetext{
Linguagem é um "produto social"; você pode conjurar uma ideia muito precisa deste produto - e, portanto, definir a linguagem, por assim dizer, materialmente na sua frente - centrando-se sobre o que está potencialmente nos cérebros de um conjunto de indivíduos (pertencentes a uma mesma comunidade) mesmo quando eles estão dormindo; podemos dizer que, em cada uma dessas cabeças é todo o produto que nós chamamos de linguagem. Podemos dizer que o objeto a ser estudado é o tesouro depositado no cérebro de cada um de nós. Sem dúvida, este tesouro, em qualquer caso, nunca se tornará absolutamente completo. Podemos dizer que a linguagem sempre funciona através de uma linguagem; sem isso, ela não existe (SAUSSURE 1993: Notebook I, 7a).
}

Sendo assim, podemos dizer que linguagem é primariamente um meio de comunicação, que necessariamente requer a inserção em um contexto social. É por isso que uma comunicação eficaz requer uma compreensão e reconhecimento das conexões entre a linguagem e as pessoas que o utilizam. Partimos do entendimento de que linguagem é um sistema elaborado por um conjunto de signos socialmente entendidos, histórica e culturalmente (BENTO 2013).

Nesta perspectiva, a representação gráfica geométrica é, para nós, uma linguagem gráfica. A linguagem gráfica é uma linguagem simbólica assim como a linguagem escrita. Todavia, diferentemente desta última, ela é representa formas através de pontos, linhas, superfícies e volumes. Dito isso, é importante salientar que a linguagem gráfica possui características peculiares e únicas porque gera uma representação (imagem) que está carregada de informações sobre a Forma a qual está representando. Dentre essas informações estão grandezas, posicionamento e outras propriedades da Forma. A linguagem gráfica encerra em si precisão, síntese e eficácia sobre as informações da forma, que de outro modo seriam quase impossíveis de serem comunicadas.

No entanto, uma vez sendo linguagem, é necessário que os sujeitos envolvidos no processo de comunicação, sejam alfabetizados em linguagem 
gráfica, para que o processo de expressão e interpretação gráfica ocorra sem perdas. Por exemplo, na arquitetura o projeto de uma casa, que é constituído de uma série de representações gráficas em forma de plantas, cortes e fachadas, contém todas as informações necessárias para construí-la. 0 que queremos dizer é que se não existisse o projeto em forma de linguagem gráfica, seria quase impossível construir a casa, ou seja, se ao invés do projeto tivéssemos um texto descrevendo as formas a serem construídas, as informações desse texto não seriam suficientemente eficazes e precisas para se construir a casa. Isso ocorre porque apenas a representação da Forma através da linguagem gráfica carrega todas as informações necessárias para a inteira compreensão dessa forma. Inclusive, a partir da representação gráfica de uma forma, podem ser extraídas informações que não estão explícitas em um primeiro momento, como por exemplo a determinação de verdadeiras grandezas de planos de um telhado a partir da representação de uma planta de coberta e um corte ou uma fachada.

O desenho nunca foi nosso objetivo final, pois sempre foi um meio, já que o foco das nossas atividades não é o desenho é sim a Forma. 0 estudo da Forma é o nosso fim. Por muito tempo se utilizou o desenho como principal tipo de representação gráfica para estudar a Forma. Talvez seja por isso que o meio e o fim se confundiram ao longo do caminho. Essa confusão torna-se ainda mais clara quando pensamos na seguinte cadeia: a Geometria Gráfica estuda a Forma através de um meio, que é a linguagem gráfica e, como linguagem, necessita de um meio de expressão, que são exatamente as representações gráficas geométricas. Historicamente o desenho foi, e ainda continua sendo, apenas o meio mais comum e democrático para nos expressarmos. Não queremos tirar, em hipótese alguma, a relevância que o desenho teve para a Geometria Gráfica. Contudo, a realidade futura pode requerer uma nova abordagem do entendimento e da representação da Forma, como seria o caminho natural da evolução das ciências e da produção do conhecimento.

Resumindo, respondendo de maneira mais objetiva e precisa à pergunta "o que fazemos", entendemos que a resposta é o estudo, o entendimento e a representação da Forma. Para estudar a Forma utilizamos a representação gráfica geométrica, que se constitui em um tipo de linguagem gráfica.

\subsection{Para onde vamos? Contribuições da Geometria Gráfica para o estudo e} ensino da Forma.

O que se espera da Geometria Gráfica como ciência é que a partir do momento em que o mundo em que vivemos se modifique, surjam novas necessidades no pensar e no compreender a Forma, especialmente com o desenvolvimento da tecnologia, que vem possibilitando operações ou visualizações antes inexequíveis. Atualmente, as representações gráficas geométricas podem se dar tanto por meio do suporte gráfico convencional 
(desenho), quanto por meio do suporte gráfico digital (softwares). Tal fato abre possibilidades sem precedentes para o estudo e para a representação da Forma, uma vez que a representação gráfica geométrica digital carrega não somente as informações geométricas que lhes são intrínsecas, mas também informações que vão além da questão geométrica, como por exemplo a representação de uma parede nos softwares paramétricos. Sendo assim, o estudo da Forma através do suporte gráfico digital oferece possibilidades de representação e de informações subjacentes ainda não exploradas em todo o seu potencial.

A linguagem gráfica teve durante muito tempo o desenho como principal suporte. Contudo, atualmente esse suporte também ocorre através da representação digital, com softwares gráficos. Atualmente, as tecnologias da informação e comunicação vêm interferindo positivamente cada vez mais na área da representação gráfica. 0 processo de projeto digital e os métodos e ferramentas de modelagem da informação da construção possibilitam processos mais integrados entre as diferentes áreas responsáveis pelo processo de projeto digital. Neste sentido, o profissional que outrora tinha uma formação muito particular em uma área, seja design, arquitetura, cálculo estrutural, etc., precisa agora se inserir em uma equipe interdisciplinar, na qual os profissionais terão habilidades específicas nas suas áreas do conhecimento, mas precisarão de habilidades em áreas como programação computacional, simulação computacional aplicada à Forma, modelagem paramétrica, colaboração, projeto integrado, interoperabilidade, prototipagem rápida e fabricação digital.

A modelagem da informação e fabricação digital aplicada à Forma se constituem em tecnologias e ferramentas usadas na modelagem e fabricação dos objetos construídos, sejam estes voltados para a Arquitetura, o Design, a Engenharia ou qualquer outra área que tenha a Forma como objeto principal. A imersão no mundo as tecnologias contemporâneas de modelagem e fabricação digital têm mudado o perfil dos profissionais que utilizam a Forma. No entanto, todas essas inovações ainda não estão sendo exploradas com relação à Geometria Gráfica como ciência. Acreditamos que a fabricação digital tem ainda muito a contribuir no pensar e estudar a Forma. Talvez esse seja um caminho importante para a Geometria Gráfica em um futuro bem próximo.

Nessa perspectiva, a modelagem e a fabricação digital surgem como meios para conceber, estudar, projetar e trabalhar a Forma nas mais diferentes áreas do conhecimento humano, promovendo assim o desenvolvimento de um pensamento inovador atrelado à tecnologia e influenciando definitivamente os processos de criação e produção da forma. A consequência natural desse processo é que o papel do "desenho" do objeto construído (2D) passa a ser substituído pelo Modelo Digital (3D com informação pendurada) que incorpora conceitos de simulação computacional, essenciais para a busca da melhoria do desempenho do objeto construído.

Nas considerações do item 2.2 vimos que o desenho ainda é visto tanto como o processo, como o resultado. Processo, no que diz respeito a uma superfície marcada pelo uso de uma ferramenta. Uma pessoa pode desenhar 
sobre qualquer superfície, desde que essa superfície possa ser marcada para que haja a distinção entre o desenho e a própria superfície. E resultado, no que diz respeito à imagem final obtida, ao produto final, o produto produzido pelo ato de desenhar, a superfície marcada.

Porém, levando essa reflexão para o mundo digital e traçando um paralelo com essa primeira reflexão, temos que, quando se trata da representação gráfica geométrica digital, a Forma é representada não só pela linguagem gráfica, mas também por uma linguagem computacional e, nesse ponto, há uma fusão de duas linguagens. Atualmente, diversos softwares gráficos permitem a representação de formas sob essa ótica. Surge então o seguinte questionamento: estamos desenhando quando estamos representando uma forma e um software gráfico? Acreditamos, por tudo que ficou esclarecido sobre desenho, que não. E é exatamente nesse ponto que podemos perceber uma mudança no paradigma nos modos de representar a Forma, porque esses novos modos abrem novas janelas de reflexão. Por exemplo, estudamos teoricamente que a reta é infinita. No entanto, quando desenhamos a representação dessa reta em um papel, temos como limite a própria superfície do papel, podemos até fazer menção a infinitude dessa reta colocando setas nas suas extremidades. Já quando vamos representar essa mesma reta em um software computacional como o AutoCad ou Sketchup podemos representá-la em toda sua infinitude. Consequentemente, a representação se aproxima da sua definição e isso é uma abordagem inovadora para a Geometria Gráfica como ciência.

\section{CONSIDERAÇÕES FINAIS}

Como visto até aqui, a Geometria Gráfica é uma ciência. Nosso o objeto teórico e empírico de trabalho se constitui em um meio de aplicação para muitas outras áreas. Esse meio é a Linguagem Gráfica que representa a Forma, seja nas áreas de Arquitetura e Urbanismo, Artes, Design, Engenharias e Expressão Gráfica ou outras que utilizem a Forma como objeto. Como ciência, a Geometria Gráfica encontra-se em um estado adormecido porque seu desenvolvimento até aqui é suficiente para compreender a realidade vigente. Não obstante, a Geometria Gráfica - enquanto área de ensino que tem como foco a linguagem gráfica - está passando por um processo de modificação ocasionado pelas novas tecnologias digitais, que tem propiciado uma mudança de paradigma na questão da representação da forma.

As tecnologias digitais instituíram possibilidades inovadoras de representar a forma. De fato, estamos vivenciando uma reflexão epistemológica, pois somos um veículo para muitas áreas. Desse modo, a linguagem gráfica utiliza algumas tecnologias de computação gráfica que têm permitido que Formas - antes inexequíveis por não possuírem representação amparada na Geometria Gráfica - sejam possíveis de serem representadas e executadas hoje em dia. Acreditamos, assim, que a Geometria Gráfica como ciência e como objeto do ensino é, e será sempre, alvo de uma constante inovação, assim como as tecnologias que a alimenta. 
Como foi mencionado acima, muitas áreas do conhecimento utilizam a Geometria Gráfica como um meio. Contudo, embora colaborando com diversas áreas, não temos a oportunidade de nos debruçarmos sobre o nosso objeto teórico e empírico como deveríamos. Precisamos criar uma ambiência necessária para realizar estudos sobre a Forma em suas múltiplas variações e desdobramentos. Mas essa construção só será plena e possível quando alcançarmos algum tipo de consenso sobre de quem somos, pois precisamos estabelecer, criar, condensar e fortificar nossa identidade como área específica do conhecimento humano. Logicamente que a pesquisa e o ensino nessa área contribuirão de maneira excepcional para esse processo. Até lá teremos uma identidade fragmentada e inserida em outras áreas de conhecimento.

Finalizando, podemos dizer que as quatro perguntas elencadas nesse texto se traduzem da seguinte maneira. Em primeiro lugar, a Geometria Gráfica encontra-se atualmente em um momento de desvalorização da sua importância devido aos caminhos históricos que nos trouxeram até aqui, assim como pela fragmentação do entendimento da nossa identidade. Em segundo, a Geometria Gráfica fica melhor entendida quando definida como uma ciência que se traduz em representações gráficas (Isto sem levar em consideração os novos modos de representação digital). Em terceiro, somos profissionais que trabalham com a Forma, seja ela como objeto de estudo ou meio para representar graficamente formas geométricas, que são amplamente utilizadas em outras áreas do conhecimento humano. Por fim, chegamos ao questionamento ainda em discussão, sobretudo do ponto de vista epistemológico, que são os caminhos pelos quais a Geometria Gráfica terá que percorrer para se adequar e se estabelecer como área do conhecimento que trabalha a Forma nas suas mais variadas acepções.

\section{REFERÊNCIAS BIBLIOGRÁFICAS}

BARBOSA, Ana Mae. Resenhando o desenho: educação, política e história. São Paulo: Cortez, 2015.

BARROS, Thyana F. G.; BELLEMAIN, Franck G. R. Nova Licenciatura em Expressão Gráfica: parcerias para um futuro promissor. In:Anais $\mathbf{X}$ International Conference on Graphics Engineering for Artsand Design / XXI Simpósio Nacional de Geometria Descritiva e Desenho Técnico. Graphica 13. Florianópolis, 2013.

BENTO, Alexandra. Geometria Descritiva: aprendizagem de uma nova linguagem. Dissertação (Mestrado). Universidade Lusófona de Humanidades e Tecnologias. Escola de Comunicação, Arquitetura, Artes e Tecnologias da Informação. Curso de Ensino das Artes Visuais, 2013.

BRASIL. Lei de Diretrizes e Bases da Educação Nacional: lei no 4024, de 20 de dezembro de 1961. Brasília: Câmara dos Deputados, 1961. 
BRASIL. Lei de Diretrizes e Bases da Educação Nacional: lei no 5692, de 11 de agosto de 1971. Brasília: Câmara dos Deputados, 1971.

BRASIL. Lei de Diretrizes e Bases da Educação Nacional: lei no 9.394, de 20 de dezembro de 1996. Brasília: Câmara dos Deputados, 1996.

BRASIL. Secretaria de Educação Fundamental, Parâmetros Curriculares Nacionais: Matemática. Brasília: MEC/SEF, 1997.

BUENO, Beatriz Piccolotto Siqueira. Desenho e desígnio: o Brasil dos engenheiros militares (1500-1822). São Paulo, Edusp, FAPESP, 2011.

CHAPUT, Frère Ignace. Elementos de geometria: contendo noções sobre as curvas usuais. Rio de Janeiro: F. Briguiet e Cia, 1954.

CNPq. Tabela de Áreas do Conhecimento. Disponível em: $<$ http://www.cnpq.br/documents/10157/186158/TabeladeAreasdoConheci mento.pdf $>$. Acesso em: 22 ago. 2018.

COSTA, Mario Duarte e COSTA, Alcy Paes de Andrade Vieira. Geometria gráfica tridimensional: sistemas de representação. vol. 1. 3ed. Recife: Editora Universitária da UFPE, 1996.

DESENHO. Michaelis: dicionário brasileiro da língua portuguesa. Disponível em https://michaelis.uol.com.br/moderno-portugues/busca/portugues-

brasileiro/desenho/. Acesso em 19 set. 2018.

FÜRKOTTER, M.; MORELATTI, M. R. M. A Geometria da Tartaruga: uma introdução à Linguagem LOGO. In: Anais SIMPÓSIO DE MATEMÁTICA, 4, 2009, Presidente Prudente, 2009. p. 1-29.

GARDNER, Howard. Inteligência Espacial. In: GARDNER, Howard (Org.). Estruturas da Mente: a teoria das inteligências múltiplas. Porto Alegre: Artes Médicas Sul, 1994.

HOUAISS, Antônio; VILLAR, Mauro de Salles. Mini dicionário da língua portuguesa. 4.ed. rev.e aumentada. Rio de Janeiro: Objetiva, 2010.

LORENZATO, S. Educação infantil e percepção matemática. Campinas: Autores Associados, 2006.

LORENZATO, S. Porque não ensinar Geometria? Educação Matemática em Revista. v. 3, n. 4, p. 3-13, 1995.

MARQUES, Filipe; FLORES, Paulo; SOUTO, Antônio P. Desenho e Representação Gráfica: introdução ao desenho técnico. Universidade do Minho Escola de Engenharia, Guimarães, 2017.

NASSER, L, et al. Geometria segundo a teoria de van Hiele. 3 ed. Instituto de Matemática/UFRJ: Projeto Fundão, 2000.

PAVANELlO, Regina Maria. 0 Abandono do Ensino de Geometria: uma visão histórica. Dissertação (Mestrado). Faculdade de Educação, UNICAMPSP, 1989. 
PAVANELLO, Regina Maria. 0 abandono do ensino de geometria no brasil: causas e consequências. Revista, Zetetiké - 17, ano 1, volume 1, 1993.

PIAGET, J.; INHELDER, Bärbel. A Representação do espaço na criança. Bernardina Machado de Albuquerque (Trad.). Porto Alegre: Artes Médicas, 1993.

SAUSSURE, F.Saussure's Third Course of Lectures on General Linguistics(1910-1911) from the notebooks of Emile Constantin. Komatsu, E.; Harris, R. (eds.). Oxford-New York-Seoul-Tokyo, Pergamon Press, 1993.

ULBRICHT, Sérgio Murilo. Geometria e desenho: história, pesquisa e evolução. Florianópolis, 1998.

WONG, Wucius. Princípios de forma e desenho. São Paulo, Editora Martins Fontes, 1998. 